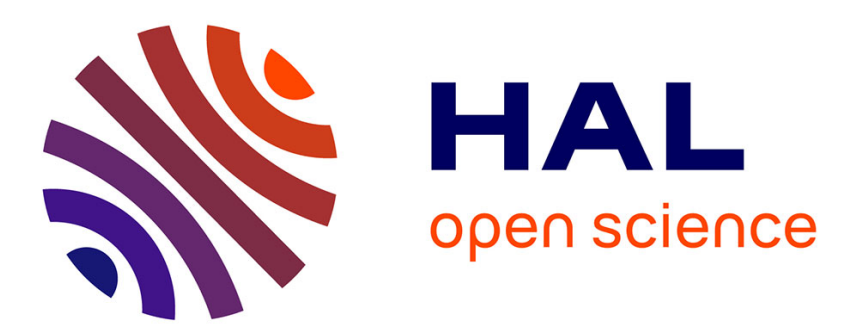

\title{
Estuary-on-a-chip Unexpected results for the fate and transport of nanoparticles
}

Julien Gigault, Marianne Balaresque, Hervé Tabuteau

\section{To cite this version:}

Julien Gigault, Marianne Balaresque, Hervé Tabuteau. Estuary-on-a-chip Unexpected results for the fate and transport of nanoparticles. Environmental science.Nano, 2018, 5 (5), pp.1231-1236. $10.1039 / \mathrm{c} 8 \mathrm{en} 00184 \mathrm{~g}$. hal-01809059v2

\section{HAL Id: hal-01809059}

\section{https://hal-univ-rennes1.archives-ouvertes.fr/hal-01809059v2}

Submitted on 11 Sep 2018

HAL is a multi-disciplinary open access archive for the deposit and dissemination of scientific research documents, whether they are published or not. The documents may come from teaching and research institutions in France or abroad, or from public or private research centers.
L'archive ouverte pluridisciplinaire HAL, est destinée au dépôt et à la diffusion de documents scientifiques de niveau recherche, publiés ou non, émanant des établissements d'enseignement et de recherche français ou étrangers, des laboratoires publics ou privés. 


\section{Estuary-on-a-chip: unexpected results for nanoparticles fate and}

\section{2 transport}

3 Julien Gigault $^{1 *}$, Marianne Balaresque ${ }^{1}$, Hervé Tabuteau* ${ }^{2}$,
$4{ }^{1}$ Laboratoire Géosciences Rennes,
92 Institut de Physique de Rennes,
5 UMR6118 CNRS/Université de Rennes1, 10 UMR6251 CNRS/Université Rennes 1, 6263 Av. Général Leclerc, 35000 Rennes
11263 Av. Général Leclerc, 35000 Rennes
7 *julien.gigault@univ-rennes1.fr
12 *herve.tabuteau@univ-rennes1.fr 8

\section{Abstract}

14 The aim of this work is to evaluate the influence of a spatial salinity gradient, as encountered 15 in an estuarine when fresh water meets salty one, on the aggregation features of fullerene nanoparticles aggregates $\left(\mathrm{nC}_{60}\right)$. To model these environmental conditions, we design a

17 specific microfluidic device. In literature, physical phenomena occurring in estuarine area, 18 such as the salinity gradient and the flow conditions, were never considered. Our results suggest that even a short time exposure (couple of seconds) to a salinity gradient, i.e. dynamical spatial conditions, profoundly affects the aggregation properties of nanoparticles and therefore their environmental behavior and fate. It appears that a salinity gradient could enhanced the stability of nanoparticles, especially at high ionic strength (closed to the seawater level one). Contrary to the common approach of particle aggregation in the lab in environmental conditions, our study shows the need to reconsider the spatial and temporal variation of abiotic parameters (ionic strength, $\mathrm{pH}$, organic matter concentration) in the understanding and the evaluation of nanoparticles environmental fate and transportation

27 mechanisms.

29 Keywords: nanoparticles, fate, estuary, aggregation, microfluidic, lab-on-a-chip 


\section{Introduction}

2 Because the main route of contaminant transport is river, estuarine systems are one of the most targeted environmental compartment. Those ones are known to play a decisive role in

4 the conditioning of the colloidal materials life cycle ${ }^{1,2}$. Estuarine systems are characterized by

5 specific physical and chemical conditions: salinity gradient, wastewater income, organic

6 matter, and human pressure (industrial and agricultural activities). From all these parameters

7 the ionic strength, characterized by the salinity, and the organic matter are the main 8 parameters that affect the stability of micro-nanoscale materials ${ }^{1,3}$.

9 Over the last ten years, the influence of the ionic strength (IS) on the physical and chemical properties of nanoparticles is one of the most studied parameter, for both carbon-based (fullerene, carbon nanotubes) $)^{4-9}$ and metal-based (Ag, $\mathrm{Au}, \mathrm{TiO}_{2}$ ) nanomaterials ${ }^{10-14}$. To do so, the kinetic of nanoparticles aggregation is generally determined by monitoring their size evolution according to the time after an addition of a known concentration of electrolyte in the bulk. However, since this measurement is made while the bulk salt concentration is supposed to be homogeneous, it cannot be representative to what happens in the natural environment. Indeed, these experiments are performed in static or large scale dynamic reactors (such as columns) that are not representative of the natural conditions in which there are spatial and temporal variations of the salt concentration. Indeed, the major issue in the environmental media studies (in bulk liquid and porous media) is the limited applicability to the real dynamic process affecting the transport of particles at environmental scale. More generally NPs behaviors in the environment results from various physical and chemical

22 heterogeneities that the NPs come across. For estuarine system, the salinity gradient is one of these spatial and temporal heterogeneities, and up to now nobody has considered its influence on the fate of NPs. 
1 Recently, new experimental methods and capacities, based on microfluidic devices, are

2 opening the door to environmental science for better understand the fate of species in dynamic

3 systems, closer to real natural conditions ${ }^{15-18}$. The aim of this work is to evaluate the fate of

4 nanoparticles, using fullerene aggregates $\left(\mathrm{nC}_{60}\right)$, in a salinity gradient. To do that we

5 developed a specific microfluidic device to simulate an environmentally representative

6 salinity gradient. Our results, compared to classical batch experiments, demonstrates a

7 different and specific aggregation kinetics, which raise new questions and concerns of the

8 existing knowledge on the environmental fate of nanoparticles in estuarine system.

9

10

11

12

13 Information, Fig. S1).

\section{Experimental}

\section{Sample preparation}

$\mathrm{nC}_{60}$ were prepared according to classical procedure previously described ${ }^{19-21}$. Typically, 80 mg of $\mathrm{C}_{60}$ powder (VWR, Fontenay-sous-Bois) were placed in an Erlenmeyer flask with 200 $\mathrm{mL}$ of deionized (DI) water (18.2 $\mathrm{M} \Omega . \mathrm{cm}$ at $\left.25^{\circ} \mathrm{C}\right)$ and continuously stirred for 2 weeks. Finally, the final fullerene aggregates solution $\left(\mathrm{nC}_{60}\right)$ was filtered at $0.45 \mu \mathrm{m}$ to remove large aggregates. The final concentration of $\mathrm{nC}_{60}$ is $7.2 \pm 0.7 \mu \mathrm{g} \mathrm{g}^{-1}$ and was characterized by both Total Organic Carbon analyzer (Shimadzu, TOC-Vcph) and UV-Vis (Perkin Elmer spectrophotometer, Lambda 650). The corresponding size distribution of the $\mathrm{nC}_{60}$ initial stock solution is $\mathrm{d}_{\mathrm{zH}}=180.7 \mathrm{~nm}$ (with a polydispersity index, $\mathrm{PDI}=0.07$ ) and is determined by in-situ dynamic light scattering (Vasco-Flex, Cordouan Technologies, France). Preparation of $\mathrm{nC}_{60}$ solutions were replicated 8 times with similar size distribution (see Electronic Supplemental

\section{Microfluidic reactor design and operation}


1 We design a microfluidic device to simulate the estuarine salinity gradient (figure 1). We used

2 standard soft lithography to make this microfluidic channel ${ }^{22}$. First we used a negative

3 photoresist resin (Su8 2050 Microchem) that was spin coated on a silicon wafer, heated and

4 cured with UV light through a mask on which the outline of the channel is printed. The resin

5 is again heated and developed in a bath of PGMEA to remove the uncured part of the resin.

6 Thereafter we cast polydimethylsiloxane (PDMS, Sylgard 184 silicone elastomer kit, Dow

7 Corning) on the SU8 master. Once cured at $70^{\circ} \mathrm{C}$ for an hour the PDMS slab becomes solid, it

8 is removed from the mold and punched to get the inlets and outlets holes of our channel. Then

9 the channel is sealed by gluing the slab on a glass plate using a plasma cleaner (Harrick

Plasma). This process renders the surface of the PDMS channel hydrophilic. To recover a hydrophobic surface we put the microfluidic device in an oven at $120^{\circ} \mathrm{C}$ for two hours. We inject fluid in the channel thanks to syringe pumps (KDS) at the inlets. In a typical experiment, we first saturate the channel with pure water and then connect pure water or salty on one inlet and a dilute fullerenes suspension on the other. The flow rates were controlled by syringe pump from 0.1 to $1.0 \mathrm{ml} / \mathrm{h}$. At those rates the channel is filled in less than a couple of seconds.

The microfluidic device is composed of $5 \mathrm{~mm}$ long and $200 \mu \mathrm{m}$ wide inlets and outlets ("A out" and "B out") arms on either side of a $3 \mathrm{~cm}$ long channel with a width of $800 \mu \mathrm{m}$ and a but we get similar results over a wide range of flow rates $(0.1$ to $1.0 \mathrm{ml} / \mathrm{h})$.

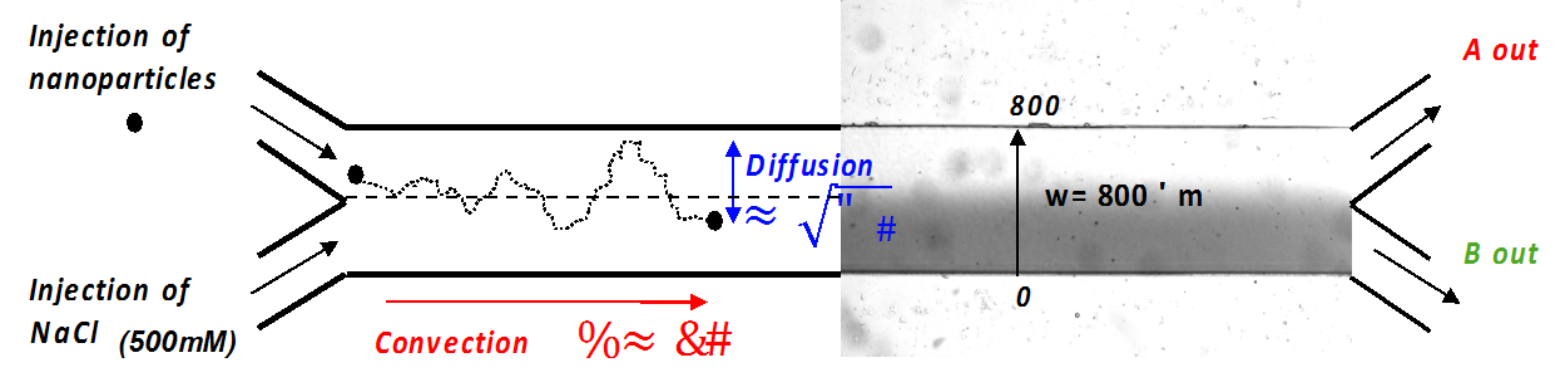


Figure 1: Scheme of the microfluidic dynamic and operation. At the entrance of the MD, two inlets are dedicated for the injection of $\mathrm{nC}_{60}$ (nanoparticles) in DI water and for the $\mathrm{NaCl}$ with salinity closed to Estuary mouth (500 mM). Two outlets are identified, Aout and Bout, and are symmetric to the two entrances in term of geometry.

The Figure 1 illustrate the microfluidic device used to simulate the estuarine salinity gradient.

5 Each microfluidic experiment are performed in three steps:

1-Salt calibration. We first inject pure water and a salty blue dye solution (Patent Blue from Sigma Aldrich, \#198218). This configuration allows us to visualize the salinity gradient on the image that can be analyzed (Fig. S2 top). We checked that the dye does not affect the salinity gradient. The average salt concentration at the two outlets were determined thanks to the UV-spectra of the $\mathrm{NaCl}$ stock solution for various salt concentration (Fig. S2 middle and bottom). To this end we collect samples at both outlets during one hour and then we determine absorbance spectrum of the salty solutions.

2-Diffusion $n C_{60}$ in the $M D$. We inject, at a flow rate of $1 \mathrm{ml} / \mathrm{h}, \mathrm{nC}_{60}$ dispersed in water in one arm and pure water in the other. We collect samples at the two outlets during one hour, we stop the flow and then we determine the size distribution of the NPs. We found the same distribution for both outlets (Fig. S3). This check step confirms that $\mathrm{nC}_{60}$ diffuse around as it flows through the microchip, i.e, the particle concentration is symmetric with respect to the middle vertical plane of the straight channel.

3- $n C_{60}$ aggregates in the salinity gradient. We inject at a flow rate of $1 \mathrm{ml} / \mathrm{h}$ in each inlet arm respectively dilute suspension of $\mathrm{nC}_{60}$ in $\mathrm{DI}$ water and a salty dye solution (patent blue dissolved in $500 \mathrm{mM}$ of $\mathrm{NaCl}$ ), a salinity that is encountered in the vicinity of Estuary mouths $\left(\sim 30 \mathrm{~g} \mathrm{~L}^{-1}\right)$. In this experiment the average $\mathrm{NaCl}$ concentration is $42 \mathrm{mmol} \mathrm{L}^{-1}$ and $427 \mathrm{mmol}$ $\mathrm{L}^{-1}$ for $\mathrm{A}$ and $\mathrm{B}$ outlets, respectively. The residence time of the $\mathrm{nC}_{60}$ in the salinity gradient is lower than 3s in average. Again, after one hour of sample collection at the two outlets the flow rate was stopped and we start measuring the temporal evolution of the $\mathrm{nC}_{60}$ size distribution at the two outlets for two hours. Thereafter we compare the temporal evolution of the size distribution of the $\mathrm{nC}_{60}$ aggregates with that of a batch experiment as described in 
1 literature, i.e. dropwise concentrated $\mathrm{NaCl}$ dispersed into a $\mathrm{nC}_{60}$ solution and then manually

2 stirred. All the experiments were replicated five times using for each replicate a new $\mathrm{nC}_{60}$

3 stock solution and $\mathrm{NaCl}$ preparation.

4

\section{Size characterization by Dynamic Light Scattering}

We performed dynamic light scattering measurements within the collection vials connected to both outlets in order to both monitor and determine in real time the presence and the size distribution of fullerene nanoparticles aggregates transported through the microchip.

Thanks to an optical fiber remote head, the system used in this work is a dedicated DLS system for contact less in-situ measurement (see ESI, Fig S4). For the nanoparticles setup, DLS specifications were: laser of $658 \mathrm{~nm}$ with a $60 \mathrm{~mW}$ power; the scattering angle is $170^{\circ}$, the working distance is fixed at $80 \mathrm{~mm}$.

For $\mathrm{nC}_{60}$ size kinetics determination with the $\mathrm{NaCl}$, the intensity-weighted mean diameter (i.e. called the $\mathrm{z}$-average hydrodynamic diameter, $\mathrm{d}_{\mathrm{zH}}$ ) variation was used and was derived using the Cumulants algorithm from the auto-correlation function (ACF) $)^{23,24}$. Cumulants is the simplest analysis of the ACF and is ideal to determine the average particle size of a population. For obtaining size distribution from the autocorrelation curve (ACF function), two algorithms were used: Sparse-Batesian-Learning (SBL) and the Cumulants. Cumulants algorithm is one of the most famous and recognized method for determining size distribution of polydisperse sample (Kopel). In the case of environmental and/or highly polydisperse sample, Cumulants method presents several disadvantages. Indeed, this algorithm doesn't permit independent determination of the long-time baseline of the ACF function and can lead to inconsistent results when different numbers of data points are included in the fit. Using the baseline as a floating parameter makes it possible to detect problems in the data and to fit data when a little bit of noise is present, which our case. The $d_{H}$ size distribution was determined using the Sparse Bayesian learning (SBL) algorithm for the Laplace transform inversion ${ }^{25}$. 
1 This algorithm is adapted to identify, discriminate and determine the presence of several

2 polydisperse population from the ACF coming from the scattered light ${ }^{25}$. More specifically, it

3 generates a set of sparse solutions of several domains but of the same dimension. Then, it

4 superimposes these solutions to give a global solution with its dimension treated as a

5 regularization parameter. An optimal solution providing a reliable description of a colloidal

6 suspension is determined by an L-curve for selecting the suitable value of the regularization

7 parameter. So, the final result corresponds to the most probable physical solution of the

8 algorithm which position is easily defined as the inflexion of a L-curve representation. This

9 method was proved to be more robust than classical methods used to determine size

10 distribution of polydisperse sample.

\section{Results and Discussion}

13 Here our objective is to show that the aggregate growth of nanoparticles depends strongly on the homogeneity of the salt concentration. To do this we compare on Figure 2 the temporal variation of the average hydrodynamic diameter, $\mathrm{d}_{\mathrm{zH}}$, of $\mathrm{nC}_{60}$ aggregates either obtained by dropwise $\mathrm{NaCl}$ into the bulk, at two concentrations 85 and $500 \mathrm{mmol} \mathrm{L}^{-1}$, (named bulk experiments, BE), or collected at the outlets of our microfluidic device (named MD), $A_{\text {out }}$ and $\mathrm{B}_{\text {out}}$, with an average salt concentration of 42 and $427 \mathrm{mmol} \mathrm{L}^{-1}$, respectively. Both salt concentration in the BE have been chosen to be very close to those obtained at the two outlets of the MD. We choose the two salt concentrations in order to be on both sides of the critical coagulation concentration (CCC) of $\mathrm{nC}_{60}$, which is between 120 and $260 \mathrm{mM}$ of sodium chloride ${ }^{4-6,26}$ according to the different formation pathways ${ }^{21}$.

23 BE is generally performed to mimic the evolution of the aggregation features of nanoparticles 24 in salty natural environments, i.e., in the ocean or in Estuaries. In this case, the aggregation of $25 \mathrm{nC}_{60}$ takes place in a spatially homogeneous salt concentration. Indeed the salt dispersed at 
1 the beginning of the experiment diffuse so quickly throughout the vial that no significant

2 aggregates growth of $\mathrm{nC}_{60}$ is observed during this homogenization process. In the $\mathrm{MD}$

3 experiment the fullerene aggregates $\left(\mathrm{nC}_{60}\right)$ quickly passed through a $\mathrm{NaCl}$ gradient and then

4 they can grow into a vial at rest, in the same conditions than those of the BE.

5 - Below the CCC of $\left(\mathrm{nC}_{60}\right)$ there is a slight increase of the aggregates sizes at the beginning of

6 the experiment ( $t<15 \mathrm{~min}$ ) for the BE and then there is no temporal evolution of $\mathrm{d}_{\mathrm{zH}}$ anymore

7 (Fig. 2a, blue circle). The screening of the surface charge is limited at electrolyte

8 concentrations below the CCC and thus $\mathrm{nC}_{60}$ aggregation is limited. In this electrolyte

9 conditions, the $\mathrm{nC}_{60}$ suspension remains quite stable.

We found similar results for the microfluidic experiment in the outlet $A_{\text {out }}$ (Fig. 2a, black circle). This is further confirmed by looking at the global size distribution summed over the total kinetics time for both types of experiment (Fig. 2b), which are very similar. The mean aggregate size is a bit larger in the $\mathrm{BE}$ than in the $\mathrm{MD}$ experiment since the salt concentration is slightly higher in the former case. However, it is worth noting that there is a small micron size population $\left(d_{z H}>1 \mu \mathrm{m}\right)$ in the MD experiment, which is not the case in the BE. We will get back to this point later on.

-Above CCC of $\left(\mathrm{nC}_{60}\right)$ the situation is completely different whether the $\mathrm{nC}_{60}$ aggregates encounter a spatial salt gradient or not (Fig. 2c). In the BE $d_{z H}$ increases over time, up to 400 nm. A similar trend was previously observed in literature, which validates our bulk experiments strategy ${ }^{26}$. As expected, above the CCC, the nanoparticle surface charge is completely screened, thus eliminating the energy barrier to aggregation. Surprisingly, for roughly the same amount of salt at the outlet B of the microchip there is only a limited aggregate growth while we are well above the CCC, $d_{\mathrm{zH}}$ increasing slightly from $170 \mathrm{~nm}$ and levels of around $260 \mathrm{~nm}$. We do not observe any further growth after two hours. Two distinct aggregate size distributions (Fig. 2d) were obtained for Bout and 500mM for the BE. For the 
$1 \mathrm{BE}$, the first population at $170 \mathrm{~nm}$ corresponds to the initial population of $\mathrm{nC}_{60}$, while the

2 second population at $450 \mathrm{~nm}$ corresponds to the $\mathrm{nC}_{60}$ aggregates induced by $\mathrm{NaCl}$. This

3 means that one part of the $\mathrm{nC}_{60}$ aggregates that belongs to this initial population has not yet

4 partake to the aggregation process. If the experiment would have last longer this first 5 population would have disappeared progressively. In the MD experiment we also have two 6 aggregate populations. However in the MD experiment, contrary to BE, the initial population 7 is predominant in the size distribution. There is only a slight shift of the average aggregate 8 size, from 170 to $250 \mathrm{~nm}$. Therefore in this case the aggregation mechanism is quite different 9 than before, for the BE. Moreover, as for $\mathrm{A}_{\text {out }}$, a micro-sized population is still observed but 10 with much larger contribution to the overall population of $B_{\text {out }}$. We suppose that there is a 11 release of micron-sized aggregates of $\mathrm{nC}_{60}$ formed in the $\mathrm{MD}$. Nevertheless, their quantity is 12 relatively low compare to the nano-sized population $(170 \mathrm{~nm})$ due to the dependence of 13 intensity of light scattered $(I)$ with size $\left(r^{6}\right)$ and concentration $c$. 

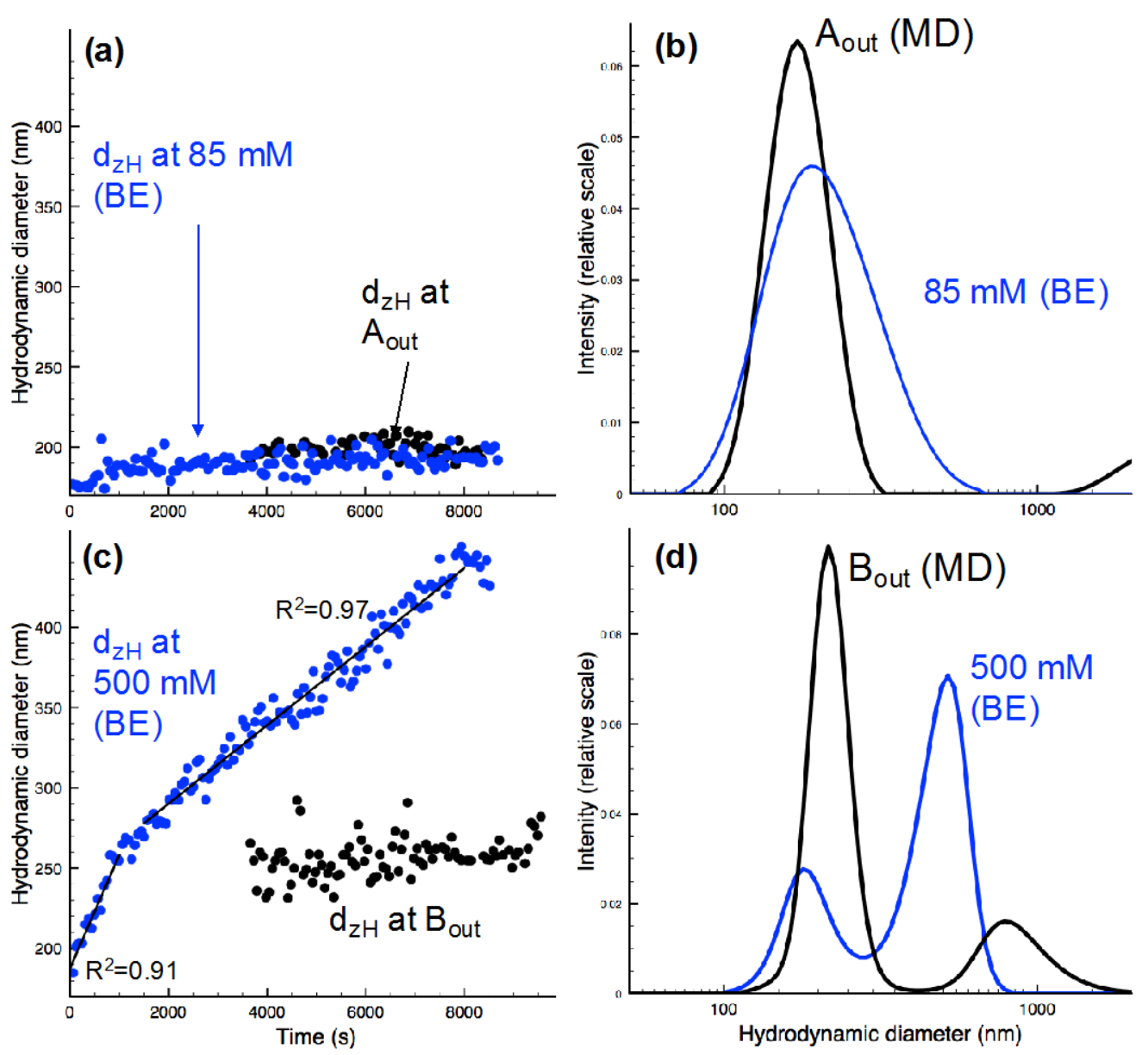

Figure 2: $(a, c)$ illustration of the z-average hydrodynamic diameter $(\mathrm{nm})$, determined by the Cumulants algorithm, according to the ionic strength using bulk experiment and the use of $M D\left(A_{\text {out }}\right.$ and $\left.B_{\text {out }}\right)(b, d)$ the average hydrodynamic diameter distribution determined by SBL algorithm and integrated along the whole duration of the kinetics (8500 and $4500 \mathrm{~s}$ for bulk an MD experiments, respectively). On (c) for $500 \mathrm{mM}(\mathrm{BE})$, there are two linear fits of the data $\left(d_{z H}=a . T\right.$, with $a=0.064$ and $a=0.023$ for larger values).

Several hypotheses can be made to explain the difference between the particle aggregation in the bulk and the microfluidic experiment.

o First, the difference between microfluidics and the bulk experiments could be explained by the Diffusion-Limited Colloidal Aggregation (DLCA) and ReactionLimited Colloidal Aggregation (RLCA) mechanisms ${ }^{27}$. Indeed, it is well known that in batch mode, DLCA is the predominant behavior, where no repulsive barrier exists between the particles and the aggregate growth rate is entirely driven by Brownian motion. DLCA induces the formation of open structure aggregates, with fractal dimension $\left(\mathrm{D}_{\mathrm{f}}\right)$ generally ranging between 1.5 and 2.0 with a linear increase of the 

aggregate size over time ${ }^{5,26}$, as we also obtained here (Fig. 2.c). In the other case, where there is a repulsive energy barrier between fullerene particles, RLCA is dominant with a limited aggregate growth, contrary to DLCA, as it was observed in case of the microfluidic experiment presented in this work. This result suggests that the salt gradient causes the $\mathrm{nC}_{60}$ aggregation according to the $\mathrm{RLCA}$ mode and thereafter remains stable in time over our experimental window.

o Secondly, during the transportation of $\mathrm{nC}_{60}$ through the microchip, after several hours of experiments and replicates larger aggregates can be formed in the salt front localized at the center of the channel corresponding to the black line in fig. 3. Indeed, this black-like deposition is characteristic of fullerene aggregates and is localized at the middle of the salt gradient. If too large aggregates could be formed, the micron-sized fraction of those sediment into the MD (Fig. 3). This hypothesis would confirm that micron-sized particles released in $\mathrm{A}_{\text {out }}$ and $\mathrm{B}_{\text {out }}$ are aggregates formed mainly within the salinity gradient in the MD. Nevertheless, this hypothesis cannot explain why the other part of the size distribution, small particles still present in $\mathrm{B}_{\text {out }}$ at high [ $\mathrm{NaCl}$ ] (i.e. $>\mathrm{CCC}$ ), do not form greater aggregates over time, as big as those observed in bulk experiments.

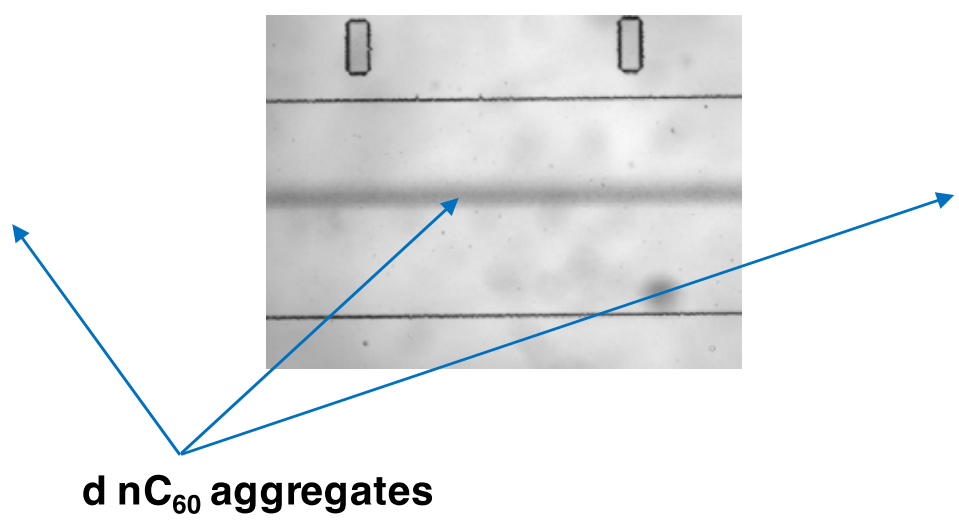

Figure 3: Illustration of the $M D$ with deposition of $n C_{60}$ micron-sized aggregates in the center of the channel (dark lines) after several cycles of operation and replicates 
2 Due to the $\mathrm{NaCl}$ concentrations used in this study, no representative electronic microscopy 3 image of the $\mathrm{nC}_{60}$ aggregates can be obtained. But, despite the different hypotheses described 4 above, it appears clearly that $\mathrm{nC}_{60}$ are transported and diffused through the salinity gradient. 5 During this short time transportation within the salinity gradient, a clear difference on the 6 aggregation behavior is identified, compared to the classical results in bulk experiments.

7

Based on these results and comparing to the literature concerning the environmental behavior of manufactured nanomaterials, several questions raised up. Indeed, both incidental and manufactured nanoparticles are expected to be released massively closed to urban system that will be eventually released in the river and finally transport through the estuarine system characterized by an increasing ionic strength. The expectations are that nanoparticles (NPs) will settle at different rate when the ionic strength increases. In literature, physical phenomena occurring in estuarine area, such as the salinity gradient and various flow conditions, were never considered. But, our results suggest that a short exposition of NP such as $\mathrm{nC}_{60}$ within the salinity gradient affects definitely their aggregation mechanisms, and therefore their environmental behavior. Secondly, the scientific community on colloids and nanoparticles agrees to the fact that an ionic strength closed to the seawater ones leads to an irreversible aggregation and a change in size (up to micrometer). Our results suggest that the salinity gradient could enhanced the stability of nanoparticles, especially at high ionic strength (closed to the seawater one). This first study shows the need to reconsider the spatial and temporal variation of abiotic parameters (ionic strength, $\mathrm{pH}$, organic matter concentration) in the 
understanding and the evaluation of nanoparticles environmental fate and transportation mechanisms.

\section{Acknowledgements}

This work was financially supported by the Interdisciplinary Mission (MI) of the French

National Center for Scientific Research (CNRS; LaCUNE and LaCUNE-2 projects) and the

Brittany Council of France (SAD program, NANOSALT project).

\section{Reference}

(1) Mayer, L. M.; Wells, M. L. Aggregation of Colloids in Estuaries. In Treatise on Estuarine and Coastal Science; 2012; Vol. 4, pp 143-160.

(2) Lasareva, E. V.; Parfenova, A. M.; Demina, T. S.; Romanova, N. D.; Belyaev, N. A.; Romankevich, E. A. Transport of the Colloid Matter of Riverine Runoff through Estuaries. Oceanology 2017, 57 (4), 520-529.

(3) Hotze, E. M.; Phenrat, T.; Lowry, G. V. Nanoparticle Aggregation: Challenges to Understanding Transport and Reactivity in the Environment. J. Environ. Qual. 2010, 39 (6), 1909-1924.

(4) Yang, Y.; Nakada, N.; Nakajima, R.; Yasojima, M.; Wang, C.; Tanaka, H. PH, Ionic Strength and Dissolved Organic Matter Alter Aggregation of Fullerene C60 Nanoparticles Suspensions in Wastewater. J. Hazard. Mater. 2013, 244-245, 582-587.

(5) Chen, K. L.; Elimelech, M. Aggregation and Deposition Kinetics of Fullerene (C60) Nanoparticles. Langmuir 2006, 22 (26), 10994-11001.

(6) Chen, K. L.; Elimelech, M. Influence of Humic Acid on the Aggregation Kinetics of Fullerene (C60) Nanoparticles in Monovalent and Divalent Electrolyte Solutions. J. Colloid Interface Sci. 2007, 309 (1), 126-134.

(7) Brant, J.; Lecoanet, H.; Wiesner, M. R. Aggregation and Deposition Characteristics of Fullerene Nanoparticles in Aqueous Systems. J. Nanoparticle Res. 2005, 7 (4-5), 545-553.

(8) Chen, Q.; Saltiel, C.; Manickavasagam, S.; Schadler, L. S.; Siegel, R. W.; Yang, H. Aggregation Behavior of Single-Walled Carbon Nanotubes in Dilute Aqueous Suspension. $J$. Colloid Interface Sci. //, 280 (1), 91-97.

(9) Gigault, J.; Grassl, B.; Lespes, G. Size Characterization of the Associations between Carbon Nanotubes and Humic Acids in Aqueous Media by Asymmetrical Flow Field-Flow Fractionation Combined with Multi-Angle Light Scattering. Chemosphere 2012, 86 (2), 177182.

(10) Badawy, A. M. E.; Luxton, T. P.; Silva, R. G.; Scheckel, K. G.; Suidan, M. T.; Tolaymat, T. M. Impact of Environmental Conditions (PH, Ionic Strength, and Electrolyte Type) on the Surface Charge and Aggregation of Silver Nanoparticles Suspensions. Environ. Sci. Technol. 2010, 44 (4), 1260-1266.

(11) Domingos, R. F.; Tufenkji, N.; Wilkinson, K. J. Aggregation of Titanium Dioxide Nanoparticles: Role of a Fulvic Acid. Environ. Sci. Technol. //, 43 (5), 1282-1286.

(12) Delay, M.; Dolt, T.; Woellhaf, A.; Sembritzki, R.; Frimmel, F. H. Interactions and 
Stability of Silver Nanoparticles in the Aqueous Phase: Influence of Natural Organic Matter (NOM) and Ionic Strength. J. Chromatogr. A //, 1218 (27), 4206-4212.

(13) Rahman, T.; George, J.; Shipley, H. J. Transport of Aluminum Oxide Nanoparticles in Saturated Sand: Effects of Ionic Strength, Flow Rate, and Nanoparticle Concentration. Sci. Total Environ. 2013, 463, 565-571.

(14) Merschel, G.; Bau, M.; Dantas, E. L. Contrasting Impact of Organic and Inorganic Nanoparticles and Colloids on the Behavior of Particle-Reactive Elements in Tropical Estuaries: An Experimental Study. Geochim. Cosmochim. Acta 2017, 197, 1-13. (15) Sun, C.; Chen, S.-T.; Hsiao, P.-J. Mapping the Salinity Gradient in a Microfluidic Device with Schlieren Imaging. Sensors 2015, 15 (5), 11587-11600.

(16) Drescher, K.; Shen, Y.; Bassler, B. L.; Stone, H. A. Biofilm Streamers Cause Catastrophic Disruption of Flow with Consequences for Environmental and Medical Systems. Proc. Natl. Acad. Sci. 2013, 110 (11), 4345-4350.

(17) Dunphy Guzman, K. A.; Finnegan, M. P.; Banfield, J. F. Influence of Surface Potential on Aggregation and Transport of Titania Nanoparticles. Environ. Sci. Technol. 2006, 40 (24), 7688-7693.

(18) Stocker, R.; Seymour, J. R.; Samadani, A.; Hunt, D. E.; Polz, M. F. Rapid Chemotactic Response Enables Marine Bacteria to Exploit Ephemeral Microscale Nutrient Patches. Proc. Natl. Acad. Sci. 2008, 105 (11), 4209-4214.

(19) Brant, J. A.; Labille, J.; Bottero, J.-Y.; Wiesner, M. R. Characterizing the Impact of Preparation Method on Fullerene Cluster Structure and Chemistry. Langmuir 2006, 22 (8), 3878-3885.

(20) Labille, J.; Masion, A.; Ziarelli, F.; Rose, J.; Brant, J.; Villiéras, F.; Pelletier, M.; Borschneck, D.; Wiesner, M. R.; Bottero, J. Y. Hydration and Dispersion of C60 in Aqueous Systems: The Nature of Water-Fullerene Interactions. Langmuir 2009, 25 (19), 11232-11235. (21) Gigault, J.; Budzinski, H. Selection of an Appropriate Aqueous Nano-Fullerene (NC60) Preparation Protocol for Studying Its Environmental Fate and Behavior. TrAC Trends Anal. Chem. 2016, 80, 1-11.

(22) Duffy, D. C.; McDonald, J. C.; Schueller, O. J. A.; Whitesides, G. M. Rapid Prototyping of Microfluidic Systems in Poly(Dimethylsiloxane). Anal. Chem. 1998, 70 (23), 4974-4984.

(23) Koppel, D. E. Analysis of Macromolecular Polydispersity in Intensity Correlation Spectroscopy: The Method of Cumulants. J. Chem. Phys. 1972, 57 (11), 4814-4820.

(24) Ross Hallett, F. Particle Size Analysis by Dynamic Light Scattering. Food Res. Int. 1994, 27 (2), 195-198.

(25) Nyeo, S.-L.; Ansari, R. R. Sparse Bayesian Learning for the Laplace Transform Inversion in Dynamic Light Scattering. J. Comput. Appl. Math. 2011, 235 (8), 2861-2872. (26) Meng, Z.; Hashmi, S. M.; Elimelech, M. Aggregation Rate and Fractal Dimension of Fullerene Nanoparticles via Simultaneous Multiangle Static and Dynamic Light Scattering Measurement. J. Colloid Interface Sci. 2013, 392, 27-33.

(27) Tang, S.; Preece, J. M.; McFarlane, C. M.; Zhang, Z. Fractal Morphology and Breakage of DLCA and RLCA Aggregates. J. Colloid Interface Sci. 2000, 221 (1), 114-123. 